
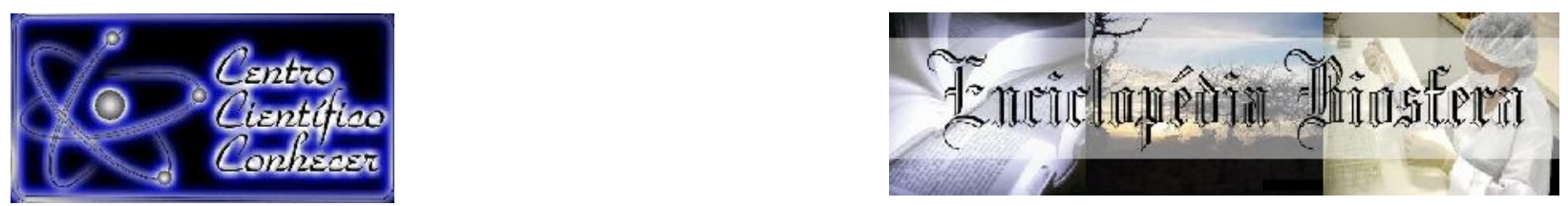

\title{
COMPARAÇÃO DA SENSIBILIDADE E ESPECIFICIDADE ENTRE DOIS MÉTODOS DE IDENTIFICAÇÃO DE Candida albicans
}

Andressa Dalólio Valente1, Thalita Costa Lopes ${ }^{1}$, Marcela Funaki dos Reis ${ }^{2}$.

1 Biomédica, Unicesumar - Centro Universitário Cesumar, Av. Guedner, 1610, Jd. Aclimação, Maringá-PR. CEP: 87050-900. (44) 3027-6360.

${ }^{2}$ Docente do curso de Medicina, Unicesumar - Centro Universitário Cesumar, Av. Guedner, 1610, Jd. Aclimação, Maringá-PR. CEP: 87050-900. (44) 3027-6360, Autor para correspondência: marcela.reis@unicesumar.edu.br

Recebido em: 15/02/2021 - Aprovado em: 15/03/2021 - Publicado em: 30/03/2021 DOI: 10.18677/EnciBio_2021A6

Candida albicans é a principal levedura causadora de infecções em humanos que pode ocasionar a morte do paciente caso não diagnosticado e tratado rapidamente. Logo, é essencial o diagnóstico rápido e confiável. No entanto, na prática clínica existem diferentes métodos que podem ser utilizados, mas que diferem quanto à sensibilidade e especificidade diagnóstica e estes aspectos estão diretamente relacionados à confiabilidade nos resultados e diretrizes de tratamento. Nesse sentido, o objetivo desta pesquisa foi realizar uma revisão integrativa da literatura com vistas a comparar a sensibilidade e especificidade dos métodos CHROMagar® e Nested-PCR para identificação de $C$. albicans, evidenciando a metodologia mais eficiente para sua identificação. Para tanto, na coleta de dados foram utilizados periódicos nacionais e internacionais indexados em diferentes bases de dados, sendo selecionados 20 artigos publicados entre os anos 2005 a 2020 para composição da revisão. Como resultados, constatou-se que o método CHROMagar® possui, segundo a literatura, sensibilidade de $97 \%$ a $83,3 \%$ e especificidade de $97,9 \%$ para a identificação de $C$. albicans, porém apresenta limitações para identificação de espécies não-albicans como $C$. parapsilosis. Já a Nested-PCR obteve uma sensibilidade e especificidade de $100 \%$ e $97 \%$, respectivamente para a identificação de Candida spp. Demonstrando ainda vantagens em relação ao tempo e precisão diagnóstica. Nesse sentido, considera-se que o método molecular de Nested-PCR possui resultados superiores em termos de sensibilidade e especificidade quando comparado ao CHROMagar ${ }^{\circledR}$ para diagnóstico de Candida spp. No entanto, para a identificação de $C$. albicans ambas as técnicas possuem resultados satisfatórios.

PALAVRAS-CHAVE: Diagnóstico; Infecção; Levedura.

\section{COMPARISON OF SENSITIVITY AND SPECIFICITY BETWEEN TWO METHODS IDENTIFICATION OF Candida albicans}

\begin{abstract}
Candida albicans is the main yeast that causes infections in humans that can cause the death of the patient if not diagnosed and treated. Therefore, a fast and reliable diagnosis is essential. However, in clinical practice there are different methods that
\end{abstract}


can be used, but they differ in terms of sensitivity and diagnostic specificity and these aspects are directly related to the reliability of results and treatment guidelines. In this sense, the objective of this research was to carry out an integrative literature review in order to compare the sensitivity and specificity of the CHROMagar ${ }^{\circledR}$ and NestedPCR methods for the identification of $C$. albicans, showing the most efficient methodology for its identification. For both data collection, national and international journals indexed in different databases were used and 20 articles published between 2005 and 2020 were selected to compose the review. As a result, it was found that the CHROMagar® method has, according to the literature, a sensitivity of $97 \%$ to $83,3 \%$ and specificity of $97,9 \%$ for the identification of $C$. albicans, but it has limitations for the identification of non-albicans species as $C$. parapsilosis. NestedPCR, on the other hand, obtained a sensitivity and specificity of $100 \%$ and $97 \%$, respectively for the identification of Candida spp. It also demonstrates advantages in terms of time and diagnostic accuracy. In this sense, it is considered that the molecular method of Nested-PCR has superior results in terms of sensitivity and specificity when compared to CHROMagar® for the diagnosis of Candida spp. However, for the identification of $C$. albicans both techniques have satisfactory results.

KEYWORDS: Diagnosis; Infection; Yeast.

\section{INTRODUÇÃO}

Candida é a principal levedura causadora de patologias em humanos, faz parte da microbiota normal da pele humana. No entanto, em algumas situações específicas que favoreçam o aumento de virulência como a diminuição da imunidade do hospedeiro ou procedimentos invasivos se torna oportunista e patogênica (MONTES et al., 2019; SOARES et al., 2019). Nestas condições a espécie Candida pode causar a morte do hospedeiro (MONTES et al., 2019).

Espécies como Candida albicans, Candida glabrata, Candida parapsilosis, Candida tropicalis e Candida krusei são relatadas como as principais causadoras de infecções fúngicas, sendo $C$. albicans a espécie prevalente (BONA et al., 2016; VIEIRA et al., 2018; PIGATTO et al., 2019; LONE; AHMAD, 2020). Estas infecções causadas por leveduras podem ser classificadas como superficiais, cutâneas ou sistêmicas, e ainda primárias ou oportunistas (MONTES et al., 2019; ARRIOLA; ARBO, 2020).

Entre os diferentes tipos de infecções causadas pelo gênero Candida, a candidíase vulvovaginal acomete cerca de $75 \%$ das mulheres nos Estados Unidos podendo apresentar sinais e sintomas inespecíficos dificultando o processo de diagnóstico e tratamento da infecção (AMINZADEH et al., 2016; HILLIER et al., 2020). Já a candidúria é uma infecção do trato urinário associada à presença de $C$. albicans (FAZELI et al., 2019). Ohki et al. (2020) apontaram a candidemia como outro exemplo de infecção causada por $C$. albicans caracterizada como invasiva e que atinge a corrente sanguínea dos pacientes, sobretudo aqueles que estejam internados em Unidades de Terapia Intensiva (UTI), (DADAR et al., 2018; POISSY et al., 2020). Mesmo com os avanços nos tratamentos antifúngicos a taxa de mortalidade global bruta associada à candidemia varia entre 40 e $60 \%$ devido à intervenção terapêutica tardia e diferentes comorbidades apresentadas pelos pacientes (MONCADA et al., 2020; OHKI et al., 2020; POISSY et al., 2020).

O tratamento nas infecções fúngicas, assim como em outros casos, deve ser direcionado à espécie causadora. No entanto, quando realizado de maneira 
inadequada pode gerar a seleção de cepas mais resistentes aos medicamentos e piorar a infecção (POISSY et al., 2020). Dessa forma, é possível evidenciar a importância do diagnóstico adequado e rápido para introdução de um tratamento precoce para melhora do quadro clínico do paciente (SIQUEIRA; ALMEIDA, 2018; POISSY et al., 2020). As técnicas mais utilizadas para realização da identificação de C. albicans são o CHROMagarß e a Nested- PCR (MíMICA et al., 2009).

Dentre os meios diagnósticos para Candida, Araujo et al. (2005) apontaram que os meios de cultura cromogênicos são os mais utilizados para identificação de leveduras de interesse clínico e dentre esses, o CHROMagarß é o método comumente aplicado para identificação de Candida spp. (ARAUJO et al., 2005; RIBEIRO et al., 2009). Este meio cromogênico promove a metabolização do substrato $\beta$-glicosaminidase na qual cada espécie de levedura adquire uma morfologia e cor específica permitindo dessa forma a diferenciação das diversas espécies de Candida (ARAUJO et al., 2005; RIBEIRO et al., 2009). Embora de uso comum, os meios cromogênicos demoram de dois a três dias para fornecerem os resultados e a variação nos padrões de cores das colônias resultam em um diagnóstico de menor precisão e atraso na introdução de medidas terapêuticas eficazes para o tratamento da infecção (ZHAl et al., 2018; SANKARI et al., 2019).

Nesse sentido, Siqueira e Almeida (2018) inferiram que as técnicas moleculares têm se mostrado uma alternativa para a resolução desses problemas (MÍMICA et al., 2009; ALVES et al., 2010).

Uma das técnicas moleculares utilizadas para a detecção de fungos é a Nested-PCR. Nesta técnica é analisada uma região alvo conhecida como ITS (Internal Transcribed Spacer) do DNA ribossômico que é altamente conservada em fungos o que permite a identificação das diferentes espécies de maneira específica e segura (ALVES et al., 2010; SIQUEIRA; ALMEIDA, 2018). Esta técnica possui ainda a capacidade de detectar pequenas quantidades de amostras de DNA fúngico conferindo à técnica grande precisão no reconhecimento da espécie presente (ALVES et al., 2010; SIQUEIRA; ALMEIDA, 2018).

Diante do exposto, a presente pesquisa trata-se de uma revisão integrativa de literatura com o objetivo de comparar a sensibilidade e especificidade do método CHROMagarß e do método de Nested-PCR para identificação de C. albicans, mostrando portanto qual metodologia é mais eficiente para a identificação.

\section{MATERIAL E MÉTODOS}

Este trabalho tratou-se de um estudo de revisão do tipo integrativa realizada no período de 20 de março de 2020 a 12 de novembro de 2020 no Centro Universitário Cesumar - Unicesumar, Maringá-PR. desenvolvido seguindo as fases de formulação do problema; coleta de dados; avaliação dos dados; análise dos dados; apresentação e interpretação dos resultados (MOHER et al., 2015). A ferramenta utilizada para realização da pesquisa foi o levantamento de artigos presentes nas bases de dados United States National Library of Medicine (PubMed), Scientific Eletronic Library Online (Scielo) e Google Acadêmico. Foram utilizados como descritores da pesquisa os termos "Identificação de Candida albicans", "Métodos de identificação de Candida spp.", "Sensibilidade e especificidade de CHROMagar®", "CHROMagar® Candida", "Métodos Cromogênicos", "Nested-PCR na identificação de Candida spp.", "Sensibilidade e especificidade de Nested-PCR para C. albicans".

Como critérios de inclusão foram adotados artigos nos idiomas português, inglês e espanhol provenientes de periódicos nacionais e internacionais, artigos que 
se relacionassem com o tema proposto, aplicação dos métodos CHROMagar® e Nested-PCR para a identificação de Candida spp. e envolvessem pesquisas com amostras biológicas oriundas de humanos com período de publicação delimitado entre 2005 a 2020. Os critérios de exclusão foram artigos que se repetiam em ambas as bases de dados, bem como artigos fora do tema de interesse e que se relacionassem a pesquisas com animais, resumos e trabalhos acadêmicos de monografias, dissertações e teses.

Desse modo, foram selecionados 300 artigos envolvendo o universo de interesse. Esses artigos passaram por análise do título, resumo e do artigo completo para verificar se contemplavam o objetivo da revisão. Após a avaliação, optou-se por utilizar para composição desta revisão 20 artigos que cumpriram os critérios de inclusão da pesquisa. Sendo assim, foi introduzido o objetivo da presente revisão integrativa dividindo o estudo em duas classes: diagnóstico por CHROMagar® e diagnóstico por Nested-PCR, correlacionando posteriormente dados encontrados em diferentes periódicos sobre sensibilidade e especificidade de cada método.

\section{RESULTADOS E DISCUSSÃO}

De acordo com os descritores pesquisados nas bases de dados foram encontrados e analisados 300 artigos, e após a leitura minuciosa e a aplicação dos critérios de inclusão e exclusão resultou em 20 artigos selecionados os quais contemplam esta revisão integrativa (Quadro 1).

QUADRO 1- Artigos utilizados para estruturação da revisão integrativa

\begin{tabular}{|c|c|c|c|c|c|}
\hline Procedência & Título do artigo & $\begin{array}{l}\begin{array}{l}\text { Título } \\
\text { periódico }\end{array} \\
\text { (volume, } \\
\text { número } \\
\text { página) }\end{array}$ & Ano & Idioma & $\begin{array}{l}\text { País do } \\
\text { estudo }\end{array}$ \\
\hline PubMed & $\begin{array}{l}\text { Risk factors for candidemia: a } \\
\text { prospective matched case- } \\
\text { control study }\end{array}$ & $\begin{array}{l}\text { Journal List: } \\
\text { Critical Care, (v. } \\
\text { 24). }\end{array}$ & 2020 & Inglês & França \\
\hline PubMed & $\begin{array}{l}\text { Candiduria in Hospitalized } \\
\text { Patients and Identification of } \\
\text { Isolated Candida Species by } \\
\text { Morphological and Molecular } \\
\text { Methods in Ilam, Iran }\end{array}$ & $\begin{array}{l}\text { Iran Journal } \\
\text { Public Health, (v. } \\
\text { 48, n. 1, p. 156- } \\
\text { 161). }\end{array}$ & 2019 & Inglês & Iran \\
\hline PubMed & $\begin{array}{l}\text { Identification of } \\
\text { Species from } \\
\text { Samples in a } \\
\text { Tertiary Hospical } \\
\text { Tenduran }\end{array}$ & $\begin{array}{l}\text { Pathogens, (v. } 8 \text {, } \\
\text { n. } 4 \text {, p. 237). }\end{array}$ & 2019 & Inglês & Honduras \\
\hline PubMed & $\begin{array}{l}\text { Detection of Candida species } \\
\text { in pregnant Chinese women } \\
\text { with a molecular beacon } \\
\text { method }\end{array}$ & $\begin{array}{l}\text { Journal of } \\
\text { Medical } \\
\text { Microbiology, (v. } \\
67 \text {, n. 6, p.783- } \\
789) .\end{array}$ & 2018 & Inglês & China \\
\hline $\begin{array}{l}\text { Google } \\
\text { Acadêmico }\end{array}$ & 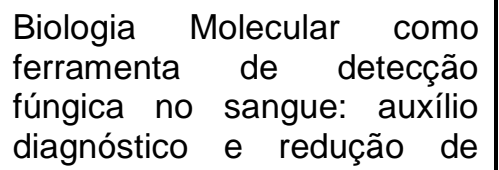 & $\begin{array}{l}\text { Archives Health } \\
\text { Sci, (v. } 25 \text {, n. } 3 \text {, } \\
\text { p. } 41-45) .\end{array}$ & 2018 & Português & Brasil \\
\hline
\end{tabular}




\begin{tabular}{|c|c|c|c|c|c|}
\hline & gastos & & & & \\
\hline PubMed & $\begin{array}{l}\text { Candidemia due to } \\
\text { uncommon Candida species } \\
\text { in children: new threat and } \\
\text { impacts on outcomes }\end{array}$ & $\begin{array}{l}\text { Scientific } \\
\text { Reports, (v. 8, n. } \\
\text { 15239, p. 1-9). }\end{array}$ & 2018 & Inglês & Taiwan \\
\hline PubMed & $\begin{array}{l}\text { Detección molecular de } \\
\text { especies de Candida en } \\
\text { especímenes de pacientes } \\
\text { hospitalizados. / Molecular } \\
\text { detection of candida species } \\
\text { from hospitalized patient's } \\
\text { specimens. }\end{array}$ & $\begin{array}{l}\text { Gaceta médica } \\
\text { de México, (v. } \\
\text { 153, n. 5, p. 581- } \\
\text { 589). }\end{array}$ & 2017 & Espanhol & México \\
\hline PubMed & $\begin{array}{l}\text { Aproximación diagnóstica y } \\
\text { terapéutica a la candidiasis } \\
\text { intraabdominal }\end{array}$ & $\begin{array}{l}\text { Revista } \\
\text { Espanhola de } \\
\text { Quimioterapia, } \\
\text { (v. 29, n. 1, p. } \\
\text { 52-55). }\end{array}$ & 2016 & Espanhol & Espanha \\
\hline $\begin{array}{l}\text { Google } \\
\text { Acadêmico }\end{array}$ & 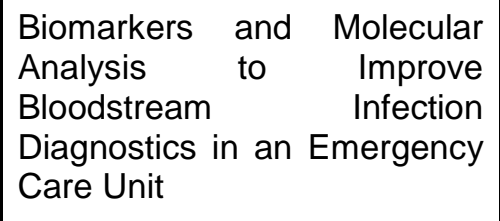 & $\begin{array}{l}\text { Bloodstream } \\
\text { Infection } \\
\text { Diagnostics, (v. } \\
9, \text { n. 1, p. 1-7). }\end{array}$ & 2014 & Inglês & Portugal \\
\hline PubMed & $\begin{array}{l}\text { Evaluation of chromogenic } \\
\text { media and seminested PCR } \\
\text { in the identification of Candida } \\
\text { species }\end{array}$ & $\begin{array}{l}\text { Brazilian Journal } \\
\text { of Microbiology, } \\
\text { (v. } 45, \text { n. } 1, \text { p. } \\
\text { 255-262). }\end{array}$ & 2014 & Inglês & Egito \\
\hline Scielo & $\begin{array}{l}\text { Identificação por PCR e } \\
\text { sensibilidade a antifúngicos } \\
\text { de isolados clínicos vaginais } \\
\text { de Candida sp. }\end{array}$ & $\begin{array}{l}\text { Revista da } \\
\text { Sociedade } \\
\text { Brasileira de } \\
\text { Medicina } \\
\text { Tropical, (v. 43, } \\
\text { n. 5, p. 575-579). }\end{array}$ & 2010 & Português & Brasil \\
\hline $\begin{array}{l}\text { Google } \\
\text { Acadêmico }\end{array}$ & $\begin{array}{l}\text { Oral Candida carriage of } \\
\text { patients attending a dental } \\
\text { clinic in Braga, Portugal }\end{array}$ & $\begin{array}{l}\text { Revista } \\
\text { lberoamericana } \\
\text { de Micologia, (v. } \\
27, \text { n. 3, p. 119- } \\
\text { 124). }\end{array}$ & 2010 & Inglês & Portugal \\
\hline Scielo & $\begin{array}{l}\text { Identification of Candida spp. } \\
\text { by Phenotypic Tests and PCR }\end{array}$ & $\begin{array}{l}\text { Brazilian Journal } \\
\text { of Microbiology, } \\
\text { (v. 41, p. 286- } \\
294,2010) .\end{array}$ & 2010 & Inglês & Brasil \\
\hline $\begin{array}{l}\text { Google } \\
\text { Acadêmico }\end{array}$ & $\begin{array}{l}\text { Seminested PCR for } \\
\text { detection and identification of } \\
\text { Candida species directly from } \\
\text { blood culture bottles }\end{array}$ & $\begin{array}{l}\text { New } \\
\text { Microbiologica, } \\
\text { (v. 33, p. 57-62). }\end{array}$ & 2010 & Inglês & Turquia \\
\hline PubMed & $\begin{array}{l}\text { Evaluation of nested and real- } \\
\text { time PCR assays in the } \\
\text { diagnosis of candidemia }\end{array}$ & $\begin{array}{l}\text { Journal } \\
\text { Compilation: } \\
\text { Clinical } \\
\text { Microbiology and } \\
\text { Infection, (v. 5, p. }\end{array}$ & 2009 & Inglês & Tunísia \\
\hline
\end{tabular}




\begin{tabular}{|c|c|c|c|c|c|}
\hline & & 656-661). & & & \\
\hline $\begin{array}{l}\text { Google } \\
\text { Acadêmico }\end{array}$ & $\begin{array}{l}\text { Diferentes métodos } \\
\text { fenotípicos para isolamento e } \\
\text { identificação de espécies de } \\
\text { Cândida }\end{array}$ & $\begin{array}{l}\text { Robrac (v. 18, n. } \\
45 \text {, p. 18-26). }\end{array}$ & 2009 & Português & Brasil \\
\hline $\begin{array}{l}\text { Google } \\
\text { Acadêmico }\end{array}$ & $\begin{array}{l}\text { Diagnóstico de infecção por } \\
\text { Candida: avaliação de testes } \\
\text { de identificação de espécies e } \\
\text { caracterização do perfil de } \\
\text { suscetibilidade }\end{array}$ & $\begin{array}{l}\text { Jornal Brasileiro } \\
\text { de Patologia e } \\
\text { Medicina } \\
\text { Laboratorial, (v. } \\
45 \text {, n. 1, p. 17- } \\
\text { 23). }\end{array}$ & 2009 & Português & Brasil \\
\hline $\begin{array}{l}\text { Google } \\
\text { Acadêmico }\end{array}$ & $\begin{array}{l}\text { Isolamento de Candida spp. } \\
\text { com utilização de meio de } \\
\text { cultura cromogênico } \\
\text { CHROMagar Candida }\end{array}$ & $\begin{array}{l}\text { Brazilian Dental } \\
\text { Science, (v. 12, } \\
\text { n. 4, p. 40-45). }\end{array}$ & 2009 & Português & Brasil \\
\hline $\begin{array}{l}\text { Google } \\
\text { Acadêmico }\end{array}$ & $\begin{array}{l}\text { Utilização de um meio } \\
\text { cromogênico e da técnica de } \\
\text { semi-nested PCR para } \\
\text { identificação de espécies de } \\
\text { Candida }\end{array}$ & $\begin{array}{l}\text { Semina: } \\
\text { Ciências } \\
\text { Biológicas e da } \\
\text { Saúde, (v. 27, n. } \\
\text { 2, p. 125-132). }\end{array}$ & 2006 & Português & Brasil \\
\hline Scielo & $\begin{array}{lr}\text { Identificação } & \text { das Leveduras } \\
\text { do Gênero } & \text { Candida por } \\
\text { métodos } & \text { Manuais } \\
\text { Convencionais e pelo Método } \\
\text { Cromógeno } & \text { CHROMAGAR } \\
\text { Candida. } & \end{array}$ & $\begin{array}{l}\text { Revista de } \\
\text { Patologia } \\
\text { Tropical, (v. 34, } \\
\text { n. 1, p. 37-42). }\end{array}$ & 2005 & Português & Brasil \\
\hline
\end{tabular}

Fonte: dados da pesquisa (2020)

Dos 20 artigos selecionados, três artigos foram encontrados na Scielo, nove presentes no PubMed e oito no Google Acadêmico. Percebeu-se, após a seleção dos artigos, que a maioria dos estudos relacionados ao tema de interesse foram publicados entre 2005 e 2014, o que sugere a necessidade de estudos com dados atualizados sobre o tema da pesquisa. A maioria dos estudos escolhidos foram publicados no idioma português contemplando pesquisas nacionais. Também houve artigos com origem na China, Taiwan, Irã, Honduras, México, Portugal, Tunísia, Egito, Turquia e Espanha mostrando que as infecções com Candida ssp. são um problema em vários países.

\section{A sensibilidade e especificidade do método de CHROMagar ${ }^{\circledR}$}

Existem diferentes formas para se realizar a identificação das espécies de Candida, dentre elas os métodos fenotípicos como o CHROMagar®. Este meio de cultura com adição de cromógenos possibilita diferenciar $C$. albicans de outras leveduras de interesse clínico (ARAUJO et al., 2005; MIMICA et al., 2009).

De acordo com Martins et al. (2010) ao analisarem o método CHROMagar®, - meio de cultura apresentou sensibilidade de $97,9 \%$ para $C$. albicans e especificidade de $83,3 \%$. Segundo o estudo foram observados padrões de cores não habituais das colônias para a espécie inicialmente identificada. Ademais, foram notados dois isolados que desenvolveram cor verde inicialmente e posteriormente não foram identificados como C. albicans (MARTINS et al., 2010). Essa variação no 
padrão de cores demonstra limitações de especificidade do método (RIBEIRO et al., 2009; MARTINS et al., 2010).

De acordo com Daef et al. (2014), o método CHROMagar® demonstrou uma sensibilidade de $96,9 \%$ e especificidade de $97,9 \%$ para identificação de $C$. albicans em relação a outros métodos fenotípicos convencionais demonstrando valores de sensibilidade e especificidade considerados elevados pelos autores para identificação de $C$. albicans.

No entanto, de acordo com Martins et al. (2010) as espécies $C$. glabrata e $C$. parapsilosis não foram identificadas em CHROMagar ${ }^{\circledR}$. Reconhecendo-se a limitação do meio CHROMagar® na identificação destas espécies de Candida (ARAÚJO et al., 2005; MIMICA et al., 2009; MARTINS et al., 2010; TSAI et al., 2018). Sendo que $C$. parapsilosis está entre as espécies não-albicans mais comuns entre as causadoras de infecções fúngicas invasivas (MIMICA et al., 2009; TSAI et al., 2018). Corroborando, Marinho et al. (2010) mostraram que os métodos fenotípicos são incapazes de diferenciar $C$. albicans de $C$. dubliniensis, demonstrando limitações em seu parâmetro de especificidade. Ainda de acordo com estes autores, as técnicas fenotípicas demandam maior tempo de execução, apesar de possuírem menor custo.

Esses estudos sugerem, portanto, que essa metodologia apesar de possuir bons índices de especificidade na identificação de $C$. albicans na maioria dos estudos analisados quando empregada para análise de outras espécies evidenciaram problemas de especificidade significativos, além de maior tempo para realização da técnica.

\section{A sensibilidade e especificidade do método de Nested-PCR}

De acordo com Siqueira e Almeida (2018) os pacientes hospitalizados em UTI geral e neonatal apresentaram discordância de resultados entre a técnica de hemocultura e Nested-PCR. Notou-se que todas as amostras negativas na PCR foram negativas na hemocultura, porém das 88 hemoculturas negativas, 41 (46,6\%) foram positivas pela Nested-PCR mostrando a presença de espécies de Candida mesmo em amostras negativas de hemocultura. Conforme salientam Siqueira e Almeida (2018), essa divergência pode ser explicada pela baixa sensibilidade das hemoculturas para a detecção de pequenas quantidades de micro-organismos no sangue, como é o caso das infecções sistêmicas. Levando em consideração que mesmo em hemoculturas negativas, as infecções invasivas, fúngicas ou bacterianas, podem estar presentes (LOONEN et al., 2014).

Segundo Khlifl et al. (2009), de 30 amostras clínicas positivas contendo diferentes espécies de Candida foram identificadas 11 amostras com presença de $C$. albicans tanto pelo método de hemocultura como pelo método de Nested-PCR. Evidenciando resultados concordantes e satisfatórios entre ambas as técnicas para identificação de $C$. albicans. ao comparar a eficiência diagnóstica entre as técnicas de Nested-PCR e PCR em Tempo Real para diagnóstico de pacientes com candidemia. No estudo, Khlif et al. (2009) mostraram sensibilidade de $86 \%$ e especificidade de $54 \%$ para a técnica de Nested-PCR ressaltaram que a técnica é espécie-específica e pode apresentar bons resultados de sensibilidade e especificidade quando comparada com outras técnicas de PCR. Apesar de apresentar limitações em relação a sua forma de execução em duas etapas de amplificação que torna o processo mais demorado (KHLIF et al., 2009).

A técnica de Nested-PCR, segundo Daef et al. (2014) a partir de isolados de amostras clínicas diversas apresentou em seus estudos para identificação de 
Candida spp. sensibilidade e especificidade de 100\%. Conforme salientam Çerikçioglu et al. (2010) ao compararem os resultados de hemoculturas e NestedPCR para a identificação de $C$. albicans em isolados clínicos, ambos testes demonstraram-se eficientes. Sendo que a técnica molecular obteve uma sensibilidade e especificidade de $100 \%$ e $97 \%$, respectivamente. Contudo, uma das amostras negativas em hemocultura foi relacionada contendo $C$. parapsilosis pelo método molecular (ÇERIKÇIOGLU et al., 2010). É possível concluir, que a técnica molecular apresenta maior precisão na identificação de espécies não-albicans (MIMICA et al., 2009).

Por fim, Oliveira et al. (2006) apresentaram em seus estudos que ao compararem as técnicas de CHROMagar® e Nested-PCR para a identificação de $C$. albicans o método CHROMagar® identificou 22 amostras com a presença de $C$. albicans. Enquanto a Nested-PCR identificou cerca de 24 amostras indicando assim, uma concordância entre as técnicas de 91,7 \%. Mesmo com um limiar de concordância alto, Oliveira et al. (2006) revelaram que a técnica molecular apresenta superioridade em relação ao CHROMagar® na identificação de espécies nãoalbicans, como é o caso da C. parapsilosis. Além disso, o método molecular utiliza a identificação genética por meio de amplicons, que são diferenciados em eletroforese e garantem à técnica maior sensibilidade e especificidade.

O método cromogênico possui baixo poder de detecção e menor especificidade na identificação de espécies não-albicans que são de grande importância clínica, demonstrando assim, que a cultura possui baixa sensibilidade e especificidade perante a superioridade do método molecular para identificação das diferentes espécies de Candida (LOONEN et al., 2014; CARDOSO et al., 2017). Zhai et al. (2018) apontam que quando compararam um método fenotípico tradicional com um método molecular, o segundo demonstrou-se mais sensível, com tempo de resposta menor em laboratório clínico.

Com relação ao tempo de execução, segundo Siqueira e Almeida (2018) o tempo de detecção por hemoculturas das leveduras nas amostras de sangue total foi em média de três dias após a coleta. Entretanto, para reconhecimento da espécie os resultados foram liberados no oitavo dia após a coleta do material. Quando comparado com o tempo de identificação via Nested-PCR, esta ocorreu no tempo máximo de 10 horas e cinco minutos, sendo casos positivos ou negativos e considerando todas as etapas que envolvem o processo segundo a técnica (SIQUEIRA; ALMEIDA, 2018).

Mostrou-se, portanto, que o método de Nested-PCR é ideal para o diagnóstico rápido, preciso e específico de acordo com seus resultados de sensibilidade e especificidade superiores às técnicas fenotípicas convencionais. Para a identificação de $C$. albicans, os resultados de ambas as técnicas foram satisfatórios e não possuem grandes discrepâncias, porém estudos apontam erros de precisão do método $\mathrm{CHROMagar}{ }^{\circledR}$ pela variação da coloração que as colônias podem apresentar no meio, levando à identificação errada até mesmo da espécie de C. albicans e além disso este meio de cultura não permite o isolamento de $C$. parapsilosis; o que demonstra um grande problema para o sistema de saúde.

Há diversas formas para detecção das espécies do gênero Candida, uma é por meio da positivação em hemoculturas e uroculturas que demonstram presença das leveduras (DAEF et al., 2014; SIQUEIRA; ALMEIDA, 2018). Outra forma de identificação é por meio de testes fenotípicos tradicionais que envolvem técnicas que possuem a finalidade de analisar o perfil morfológico e bioquímico destes organismos (ZHAl et al., 2018). Além disso, técnicas moleculares como a PCR, a 
PCR multiplex, Nested-PCR, PCR em tempo real e a PCR por transcrição reversa vêm ganhando destaque na identificação das diferentes espécies de Candida (ALVES et al., 2010).

O CHROMagar® é um teste fenotípico tradicional que permite a diferenciação das colônias de Candida spp. pela coloração e aspecto morfológico que cada espécie apresenta (ARAUJO et al., 2005; RIBEIRO et al., 2009). Sendo assim, a $C$. albicans adquire coloração verde, a $C$. tropicalis coloração azul, a $C$. krusei rosa e rugosa, a $C$. glabrata branca a rosada e a $C$. parapsilosis coloração rosa e morfologia lisa (ARAUJO et al., 2005; RIBEIRO et al., 2009; FREIRE et al., 2018). Esse tipo de identificação ajuda no isolamento da levedura possibilitando que várias espécies de Candida spp. sejam isoladas em uma única placa (ARAUJO et al., 2005; RIBEIRO et al., 2009).

Contudo, de acordo com Zhai et al. (2018) os testes fenotípicos geralmente levam mais de 48 horas para completar a identificação da levedura podendo ainda apresentar resultados equivocados. Isso revela menor precisão do diagnóstico e gera atrasos na introdução de medidas terapêuticas eficazes para o tratamento da infecção. Esse atraso no início do tratamento leva o paciente a ficar mais tempo internado aumentando os custos e os riscos de vida que essas infecções apresentam quando agravadas (SIQUEIRA; ALMEIDA, 2018). Sendo assim, são necessários métodos diagnósticos que permitam a identificação da levedura de forma rápida, precisa e eficaz, como os métodos moleculares (SIQUEIRA; ALMEIDA, 2018).

Em relação aos métodos moleculares, segundo Alves et al. (2010), várias abordagens estão sendo desenvolvidas para permitir uma identificação mais rápida e segura de espécies fúngicas para substituir os problemas de imprecisão e demora dos testes fenotípicos tradicionais (2010; ZHAl et al., 2018). Os métodos moleculares são capazes de identificar o DNA das leveduras que estão presentes nas diferentes amostras biológicas, e ainda possuem a capacidade de melhorar o diagnóstico deste tipo de infecção de maneira rápida e eficiente, podendo contribuir assim para a introdução de uma terapêutica adequada e que reduza as chances de tratamentos desnecessários e imprecisos, diminuindo os custos e a seleção de cepas resistentes ao tratamento (CARDOSO et al., 2017).

Segundo Montero et al. (2016), as técnicas moleculares possuem maiores vantagens para realização da identificação desses fungos, porém essas técnicas apesar de se mostrarem promissoras, ainda não se estabeleceram nos laboratórios de microbiologia como método de rotina devido seu elevado custo e à falta de padronização (MONTERO et al., 2016). No entanto, isso evidencia a necessidade de estudos como este, que mostrem a importância dessas técnicas para que mais pesquisas a respeito da padronização desses métodos sejam realizadas para melhoramento desse diagnóstico na rotina.

As técnicas moleculares realizam amplificação principalmente das sequências ITS1 e ITS2, onde se encontram regiões altamente conservadas conhecidas como 18S, 5,8S e 28S do DNA ribossômico (rDNA) e que estão presentes em fungos patogênicos e assim é possível identificar as espécies de Candida pelos diferentes formatos de PCR (OLIVEIRA et al., 2006; ALVES et al., 2010).

A Nested-PCR vem se destacando como alternativa para detecção de Candida spp. Esta técnica acontece em duas etapas de amplificação (OLIVEIRA et al., 2006; SIQUEIRA; ALMEIDA, 2018). Na primeira amplificação, utilizam-se primers universais que se anelam às regiões ITS do DNAr, sendo identificado nessa etapa o gênero Candida. Já na segunda etapa, são utilizados primers espécie-específicos 
ITS1 e ITS4, que identificam qual a espécie de Candida presente naquele material (OLIVEIRA et al., 2006; ALVES et al., 2010; SIQUEIRA; ALMEIDA, 2018).

A Nested-PCR tem se mostrado um bom instrumento para o diagnóstico laboratorial das candidíases invasivas com resultados promissores em relação a valores de sensibilidade e especificidade quando comparada aos métodos fenotípicos (SIQUEIRA; ALMEIDA, 2018; ZHAI et al., 2018).

Conforme Brito et al. (2003), o termo especificidade é definido como a capacidade que um método possui em distinguir o analito de interesse de outros componentes presentes na amostra. Já a sensibilidade, segundo Freitas et al. (2006), refere-se à habilidade de detecção do analito alvo em determinada concentração dentro de uma matriz biológica. Estes parâmetros são de grande importância para a garantia da confiabilidade dos resultados apresentados por determinado método (BRITO et al., 2003; FREITAS et al., 2006). Assim, juntamente com critérios de linearidade, exatidão, precisão e limite de detecção a especificidade e sensibilidade são parâmetros necessários para a validação de um método analítico (BRITO et al., 2003).

Os métodos moleculares como a Nested-PCR revelam índices de positividades maiores, já que a técnica consegue detectar frações mínimas de DNA fúngico circulante no momento da coleta de sangue pelo princípio de amplificação do DNA alvo presente e, assim, oferece maior sensibilidade ao diagnóstico (LOONEN et al., 2014).

Foi visto, portanto, que em ambos os testes de sensibilidade e especificidade os dois métodos, tanto o cromogênico quanto o molecular, possuem resultados satisfatórios para identificação e diagnóstico da $C$. albicans. No entanto, para a detecção de Candidas não-albicans, o CHROMagarß se mostrou uma técnica inferior à Nested-PCR, deixando a desejar na identificação de algumas cepas que são de extrema importância diagnóstica, como a $C$. parapsilosis e a $C$. dubliniensis. Por ser um método mais barato que o molecular, este acaba sendo escolhido pelos laboratórios. Entretanto, a Nested-PCR possibilita a identificação mais rápida, com grande poder de detecção e precisão. Fornecendo assim, um diagnóstico precoce, aumentando as chances de recuperação do paciente e, consequentemente, diminuindo os custos hospitalares em decorrência de uma internação mais longa.

\section{CONCLUSÕES}

Pode-se concluir que os métodos apresentaram elevada sensibilidade e especificidade para a identificação da espécie $C$. albicans, mostrando ainda alto grau de concordância entre as técnicas para o diagnóstico de infecções ocasionadas por esta espécie. Contudo, a técnica de Nested-PCR se sobressai ao método Cromogênico na identificação de candidas não-albicans, devido a sua utilização de primers espécie-específicos que tornam o diagnóstico altamente preciso e impactam em resultados superiores de sensibilidade e especificidade para a detecção de Candida spp. Por meio desse estudo, evidenciou-se a necessidade de mais pesquisas atuais sobre o tema relacionado, demonstrando a importância da NestedPCR quando se avaliar parâmetros de sensibilidade e especificidade para uma melhor identificação da espécie Candida.

\section{REFERÊNCIAS}

ALVES, I, A.; CAMARGO, F. P.; GOULART, L. S. Identificação por PCR e sensibilidade a antifúngicos de isolados clínicos vaginais de Candida sp. Revista da Sociedade Brasileira de Medicina Tropical, v. 43, n. 5, 2010. Disponível em: 
https://www.scielo.br/scielo.php?script=sci_arttext\&pid=S003786822010000500021\& lng $=$ pt\&tlng=pt.

AMINZADEH, A.; SANAT, A. S.; AKHTAR, N. S. Frequency of Candidiasis and Colonization of Candida albicans in Relation to Oral Contraceptive Pills. Iranian Red Crescent Medical Journal, v. 18, n. 10, 2016. Disponível em: $<$ https://www.ncbi.nlm.nih.gov/pmc/articles/PMC5291939/>.

DOI: $10.5812 /$ ircmj.38909.

ARAUJO, C. R.; MIRANDA, K. C.; PASSOS, X. S.; SOUZA, L. K. H.; LEMOS, J. A.; et al. Identificação das leveduras do gênero candida por métodos manuais convencionais e pelo método cromógeno chromagar candida. Revista de Patologia Tropical, v. 34, n. 1, p. 37-42, 2005. Disponível em: <https://repositorio.bc.ufg.br/xmlui/handle/ri/157>.

ARRIOLA, A.; ARBO, A. Factores de riesgo potenciales en infecciones sistémicas por Candida sp. Revista del Instituto de Medicina Tropical, v. 15, n. 2, p. 5-12, 2020. Disponível em: <http://scielo.iics.una.py/scielo.php?script=sci_arttext\&pid=S19 96-36962020000200005\&lng=en\&nrm=iso >. DOI: 10.18004/imt/2020.15.2.5.

BONA, E.; CANTAMESSA, S.; PAVAN, M.; NOVELLO, G.; MASSA, N.; et al. Sensitivity of Candida albicans to essential oils: are they an alternative to antifungal agents? Journal of Applied Microbiology. v. 121, n. 6, p. 1530-1545, 2016. Disponível em:<https://sfamjournals.onlinelibrary.wiley.com/doi/epdf/10.1111/ jam.13282>. DOI: 10.1111/jam.13282.

BRITO, N. M.; AMARANTE JUNIOR, O. P.; POLESE, L.; RIBEIRO, M. L. Validação de métodos analíticos: estratégia e discussão. Pesticidas: Revista de Ecotoxicologia e Meio Ambiente, v. 13, p. 129-146, 2003. Disponível em: <http://dx.doi.org/10.5380/pes.v13i0.3173>. DOI: 10.5380/pes.v13i0.3173

CARDOSO, J. L. C.; RIVERA, M. Á. M.; GAYOSSO, P. M.; TOVAR, L. J. M.; MARTÍNEZ, R. L.; et al. Detección molecular de especies de Candida en especímenes de pacientes hospitalizados. Gaceta Médica de México, v. 153, n. 5, p. 581-589, 2017. Disponível em: <https://gacetamedicademexico.com/frame_eng .php?id=31>. DOI: 10.24875/GMM.17002535.

ÇERIKÇIOGLUL, N.; AKSUL, B.; DAL, T. D.; DENIZL, U.; BILGEN, H.S.; et al. Seminested PCR for detection and identification of Candida species directly from blood culture bottles. New microbiologica, v. 33, p. 57-62, 2010. Disponível em: $<$ http://www.newmicrobiologica.org/PUB/allegati/2010_1/Micro1_07_Cerikcioglu.pdf>

DADAR, M.; TIWARI, R.; KARTHIK, K.; CHAKRABORTY, S.; SHAHALI, Y. et al. Candida albicans - Biology, molecular characterization, pathogenicity, and advances in diagnosis and control - An update. Microbial Pathogenesis, v.117, p.128-138, 2018. Disponível em:<https://www.sciencedirect.com/science/article/abs/pii/S0882 401017317175?via\%3Dihub>. DOI: 10.1016/j.micpath.2018.02.028.

DAEF, E.; MOHARRAM, A.; ELDIN, S. S.; ELSHERBINY, N. MOHAMMED, M. Evaluation of chromogenic media and seminested PCR in the identification of 
Candida species. Brazilian Journal of Microbiology, v. 45, n. 1, p. 255-262, 2014. Disponível em: <https://www.ncbi.nlm.nih.gov/pmc/articles/PMC4059308/\#!po $=34.2105 \mathrm{~s}$.

FAZELI, A.; KORDBACHEH, P.; NAZARI,A.; GHAZVINI,R. D.; MIRHENDI, H.; et al. Candiduria in Hospitalized Patients and Identification of Isolated Candida Species by Morphological and Molecular Methods in Ilam, Iran. Iran Journal Public Health, v. 48, n. 1, p. 156-161, 2019. Disponível em: <https://www.ncbi.nlm.nih.gov/pmc/articles/PMC6401579/>.

FREIRE, J. C. P.; RIBEIRO, E. D.; BATISTA, A. U. D.; PEREIRA, J. V.' LIMA, E. O. Presença de Candida spp. em usuários de próteses dentárias removíveis. Revista Cubana Estomatologia, v. 55, n. 4, p. 1-11, $2018 . \quad$ Disponível em: $<$ http://scielo.sld.cu/scielo.php?script=sci_arttext\&pid=S003475072018000400005\&ln $\mathrm{g}=\mathrm{es} \& \mathrm{nrm}=\mathrm{iso}>$.

FREITAS, E. I.; DE LEMOS, A. A.; MARIN, V. A. Validação de métodos alternativos qualitativos na detecção de patógenos alimentares. Ciểncia \& Saúde Coletiva, v. 11 n. $\quad 4$, p. 1073-1083, 2006. Disponível em: <https://www.scielo.br/scielo.php?pid=S141381232006000400028\&script=sci_abstra ct\&tlng=pt>. doi: 10.1590/S1413-81232006000400028>.

HILLIER, S. L.; AUSTIN, M.; MACIO, I.; MEYN, L. A.; BADWAY, D.; et al. Diagnosis and Treatment of Vaginal Discharge Syndromes in Community Practice Settings. Clinical Infectious Diseases, p. 1-6, 2020. Disponível em <https://academic.oup.com/cid/advance-article/doi/10.1093/cid/ciaa260/5826163>.

DOI: $10.1093 / \mathrm{cid} / \mathrm{ciaa260/5826163}$

KHLIFL, M.; MARY, C.; SELLAMI, H.; SELLAMI, A.; DUMON, H.; et al. Evaluation of nested and real-time PCR assays in the diagnosis of candidaemia. Journal Compilation: Clinical Microbiology and Infection, v. 15, n. 7, p. 656-661, 2009. Disponível em: <https://pubmed.ncbi.nlm.nih.gov/19438623/>. DOI: 10.1111/j.14690691.2009.02762.x.

LONE, S. A.; AHMAD, A. Inhibitory effect of novel Eugenol Tosylate Congeners on pathogenicity of Candida albicans. BMC Complementary Medicine and Therapies, v. 20, n. 131, 2020. Disponível em: <https://bmccomplementmedtherapies. biomecentral.com/articles/10.1186/s12906-020-02929-0\#centenas>.

DOI: 10.1186/s12906-020-02929-0.

LOONEN, A. J. M.; JAGER, C. P. C.; TOSSERAMS, J.; KUSTERS, R.; HILBINK, M.; et al. Biomarkers and Molecular Analysis to Improve Bloodstream Infection Diagnostics in an Emergency Care Unit. Bloodstream Infection Diagnostics, v. 9, 2014. Disponível em: <https://doi.org/10.1371/journal.pone.0087315>. DOI: 10.1371/journal.pone.0087315

MARINHO, S. A.; TEIXEIRA, A. B.; SANTOS, O. S.; CAZANOVA, R. F.; FERREIRA, C. A. S.; et al. Identification of Candida spp. by Phenotypic Tests and PCR. Brazilian Journal of Microbiology, v. 41, p. 286-294, 2010. Disponível em: <https://doi.org/10.1590/S1517-83822010000200004>.

DOI: 10.1590/S151783822010000200004. 
MARTINS, M.; HENRIQUES, M.; RIBEIRO, A. P.; FERNANDES, R.; GONÇALVES, V.; et al. Oral Candida carriage of patients attending a dental clinic in Braga, Portugal. Revista Iberoamericana de Micologia, v. 27, n. 3, p. 119-124, 2010. Disponível em: <https://pubmed.ncbi.nlm.nih.gov/20403455/>. doi: 10.1016/j.riam.20 10.03.007.

MÍMICA, L. M. J.; UEDA, S. M. Y.; MARTINO, M. D. V.; NARVARINI, A.; MARTINI, I. J. Diagnóstico de infecção por Candida: avaliação de testes de identificação de espécies e caracterização do perfil de suscetibilidade. Jornal Brasileiro de Patologia e Medicina Laboratorial, v. 45, n. 1, Rio de Janeiro, 2009. Disponível em: <https://www.scielo.br/scielo.php?pid=S1676-24442009000100005\&script=sci_ arttext>.

MOHER, D.;SHAMSEER, L.; CLARKE, M.; GHERSI, D.; LIBERATI, A.; et al. Preferred reporting items for systematic review and meta-analysis protocols (PRISMA-P) 2015 statement.Systematic Reviews, v. 1, n. 4, 2015. Disponível em: $<$ https://systematicreviewsjournal.biomedcentral.com/articles/10.1186/2046-4053-4$1>$.

MONCADA, P. A.; CANDELO, K. D.; SIERRA-RUIZ, M.; ROSSO, F.; MARTÍNEZ, L. F.; et al. Infección invasiva por Candida spp. En pacientes inmunocomprometidos: Descripción de curso clínico experiencia diagnóstica, manejo y seguimiento en centro de alta complejidad / Invasive infection by Candida spp. in immunocompromised patients: A description of clinical, diagnostics, therapeutic and follow up experience in high complexity healthcare center. Infectio, v. 24, n. 3, p. 143-148, 2020. Disponível em: <https://pesquisa.bvsalud.org/portal/resource /pt/biblio-1114857>. DOI: 10.22354/in.v24i3.858

MONTERO, A.; GILSANZ, F.; MASEDA, E. Abordagem diagnóstica e terapêutica da candidíase intra-abdominal. Revista Espanhola de Quimioterapia, v. 29, n. 1, p. 52-5, 2016. Disponível em https://www.ncbi.nlm.nih.gov/pubmed/27608315.

MONTES, K. ORTIS, B.; GALINDO, C. FIGUEROA, I.; BRAHAM, R.; et al. Identification of Candida Species from Clinical Samples in a Honduran Tertiary Hospital. Patógenos, v. 8, n. 4, p. 237, 2019. Disponível em: <https://www.mdpi.com/2076-0817/8/4/237/htm> DOI: 10.3390/pathogens8040237.

OLIVEIRA, N. C.; RAMPAZZO, R. C. P.; MINARI, M. C.; CORRÊA, P. R. C.; BIZERRA, F. C.; et al. Utilização de um meio cromogênico e da técnica de SemiNested PCR para identificação de espécies de Candida. Semina: Ciências Biológicas e da Saúde. v. 27, n. 2, p. 125-132, 2006. Disponível em: <http://www.uel.br/revistas/uel/index.php/seminabio/article/view/3511>. $\quad$ DOl: 10.5433/1679-0367.2006v27n2p125

OHKI, S.; SHIME, N.; KOSAKA, T.; FUJITA, N. Impact of host- and early treatmentrelated factors on mortality in ICU patients with candidemia: a bicentric retrospective observational study. Journal of Intensive Care, v. 8, n. 30, 2020. Disponível em: $<$ https://jintensivecare.biomedcentral.com/articles/10.1186/s40560-020-00450-7> DOI: 10.1186/s40560-020-00450-7. 
PIGATTO, G.; LOVISON, O. V. A.; CATTANI, F. Prevalência de infecções fúngicas em um laboratório de análises clínicas da cidade de Veranópolis, Rio Grande do Sul. Revista brasileira de análises clínicas, v. 51, n. 3, p. 202-207, 2019. Disponível em: <https://pesquisa.bvsalud.org/portal/resource/pt/biblio-1047635>. DOI: 10.21877/2448-3877.201900794.

POISSY, J.; DAMONTI, L.; BIGNON, A.; KHANNA, N.; KIETZELL, M. V.; et al., Risk factors for candidemia: a prospective matched case-control study. Journal List: Critical Care, v. 24, 2020. Disponível em: <https://www.ncbi.nlm.nih.gov/pmc/articles/PMC7081522/>. DOI: 10.1186/s13054020-2766-1

RIBEIRO, P. M.; ITO, C. Y. K.; JUNQUEIRA, J. C.; JORGE, A. O. C. Isolamento de Candida spp. com utilização de meio de cultura cromogênico CHROMagar Candida. Brazilian Dental Science, v. 12, n. 4, p. 40-45, 2009. Disponível em: <https://ojs.ict.unesp.br/index.php/cob/article/view/641>. DOI: 10.14295/bds.2009 .v12i4.641.

SANKARI, S. L.; MAHALAKSHMI, K.; KUMAR V. N. Chromogenic medium versus PCR-RFLP in the speciation of Candida: a comparative study. BMC Research Notes, v. 12, n. 1, p. 681, 2019. Disponível em: <https://www.ncbi.nlm.nih.gov/pmc/articles/PMC6805376/>. doi:10.1186/s13104019-4710-5

SIQUEIRA, J. P. Z.; ALMEIDA, M. T. G. Biologia Molecular como ferramenta de detecção fúngica no sangue: auxílio diagnóstico e redução de gastos. Archives of Health Sciences- AHS, v. 25, n. 3, p. 41-45, 2018. Disponível em: <http://docs.bvsalud.org/biblioref/2019/12/1046416/artigo9.pdf>. DOI: doi.org/10.176 96/2318-3691.225.3.2018.1127.

SOARES, D. M.; LIMA, E. O.; SOARES, D. M. M.; SILVA, N. F.; COSTA, N. G. M. et al. Candidíase Vulvovaginal: uma Revisão de Literatura com Abordagem para Candida albicans. Brazilian Journal of Surgery and Clinical Research, v. 25, n. 1, p. 28-34, 2019. Disponível em: <file:///C:/Users/Notebook/Downloads/2018 1204_202650.pdf>.

TSAI, M. H.; HSU, J. F.; YANG, Y. B.; LAI, M. Y.; CHU, S.M.; et al. Candidemia due to uncommon Candida species in children: new threat and impacts on outcomes. Scientific Reports, v. 8, n. 15239, 2018. Disponível em: <https://www.nature.com/articles/s41598-018-33662-x>.

VIEIRA, J. N. A. M. FEIJÓ, A. M.; BUENO, M. E.; GONÇALVES, C. L.; LUND, R. G.; et al. Evaluation of the frequency of Candida spp. in hospitalized and nonhospitalized subjects. Brazilian Journal of Biology, v. 78, n. 4, p. 644-652, 2018. Disponível em: <http://www.scielo.br/scielo.php?script=sci_arttext\&pid=S151969842018000400644\&lng=en\&nrm=iso >. DOI: https://doi.org/10.1590/1519-6984.1 69623 
ZHAI, Y.; LIU, J.; ZHOU, L.; JI,T.; MENG, L.; et al. Detection of Candida species in pregnant Chinese women with a molecular beacon method. Journal of Medical Microbiology, v. 67, n. 6, p. 783-789, 2018. Disponível em: <https://www.ncbi.n Im.nih.gov/pmc/articles/PMC6096925/>. DOI: 10.1099/jmm.0.000740. 